\title{
Characteristics of Male Family Caregivers in Japan and Their Sense of Care Burden, Capacity to Deal with Stress, and Subjective Sense of Well-Being
}

\author{
Sayoko Uemura' ${ }^{1}$ Keiko Sekido ${ }^{2}$, Tetsuya Tanioka ${ }^{3}$ \\ ${ }^{1}$ School of Human Nursing, University of Shiga Prefecture, Shiga, Japan \\ ${ }^{2}$ Department of Nursing, Kobe University Graduate School of Health Sciences, Kobe, Japan \\ ${ }^{3}$ Department of Nursing, Institute of Health Biosciences, The University of Tokushima Graduate School, \\ Tokushima, Japan \\ Email: uemura.s@nurse.usp.ac.jp
}

Received 5 August 2014; revised 20 September 2014; accepted 5 October 2014

Copyright (C) 2014 by authors and Scientific Research Publishing Inc.

This work is licensed under the Creative Commons Attribution International License (CC BY). http://creativecommons.org/licenses/by/4.0/

(c) (i) Open Access

\section{Abstract}

This study aimed to clarify the characteristics of Japanese male family caregivers in terms of their sense of care burden, their capacity to deal with stress, and their subjective sense of well-being. A survey consisting of questionnaires and interviews was conducted from March to May 2014 in the subjects' homes. Subjects were 27 Japanese males (the age range: 54 - 85) who provided home care for their family member. Caregivers who were good at relieving stress or who had a subjective sense of well-being were found to have a low care burden. The types and seriousness of diseases of the care recipients were not related to the caregivers' sense of burden, capacity to deal with stress, or subjective sense of well-being. Based on the interview results, caregivers were found to have the following characteristics: they were particular about methods of care; they learned how to provide home care by themselves; they used their social intelligence in home care; they always provided home care while keeping the future in mind; and most notably, they considered home care to be their primary occupation. On the whole, male caregivers were found to alleviate the burdens of home care by making use of the nursing-care service systems that enabled them to relieve stress and enjoy their leisure time. Caregivers considered home care to be their occupation and used their past social experiences. The workforce helped them deal with the care recipients' health conditions or day-to-day changes so that they could overcome the care burden.

\section{Keywords}

Male Family Home Caregivers, Sense of Care Burden, Capacity to Deal with Stress, Subjective Sense 


\section{of Well-Being}

\section{Introduction}

Improvements in nutrition, hygiene, education, and economics have allowed human beings to live longer. While the twenty-first century is experiencing an overall aging of society, much economic and cultural problems remain to be solved for individuals, families, and society in general [1]. Japan is experiencing rapid aging and the burdens of care for senior citizens are increasing at an unprecedented speed, so that preparing for emergency care has become a necessity [2]. It can be argued that at-home caregivers will experience greater burdens in the future because a certain percentage of the growing elderly population are sure to suffer from dementia, chronic diseases, and/or mental diseases requiring long-term nursing care. In response to this, much research has been conducted on at-home nursing care, including the development of scales to measure caregiver burden [3] and analyses of satisfaction levels of caregivers who look positively at nursing, their own conditions, and their sense of burden due to home care [4]-[7]. Also, there have been analyses of the recognition or acceptance of the role of the caregiver among those providing care [8] [9].

In 2012 in Japan, over 24\% of the general population were >65 years old and presently, Japan presently has the highest longevity rate in the world [10]. Because the number of elderly persons is rapidly increasing, today, elderly care has become the most serious problem facing the country. A previous study [11] showed that there were more females providing primary home care compared to males, which is generally considered to be a problem for females. However, in Japan, where more and more elderly females are suffering from dementia or chronic diseases, many husbands and sons are being required to take the role of primary caregiver [12] [13]. Moreover, more women have entered the workforce thereby lowering their availability for home care. It is therefore becoming increasingly important to provide support to family home caregivers. Although there are still more female caregivers (69.4\%) than males (30.6\%), the number of male caregivers is on the rise [14] thereby enhancing the need to illuminate and understand the actual condition of male family home caregivers.

This study aimed to clarify the characteristics of Japanese male family home caregivers (hereafter referred to as male caregivers) in terms of their sense of care burden, capacity to deal with stress, and subjective sense of well-being.

\section{Methods}

\subsection{Subjects}

The subjects of the study were 27 male caregivers who took care of a family member at home. All subjects were individuals receiving support from home-visit nursing stations or elderly care support center. The subjects were selected from three regional cities. As a requirement, a primary caregiver is a son or husband who answers the interview questions, and the care recipient is any family member who may have any type of chronic disease.

\subsection{Survey Methods and Contents}

The survey was conducted from March to May 2014 and consisted of questionnaires and face-to-face interviews. The questionnaires and interviews were conducted in the subjects' homes, and interviews were recorded following verbal informed consent on IC recorders (ICR-P503RM SANYO).

The survey collected demographic information such as subject's age, employment status and occupation, treatment of disease, drinking and smoking habits, hobbies, and sleeping hours. Also collected were information about the care recipients' ages, relationship to the caregivers, diseases, and degree of autonomy.

\subsubsection{Questionnaires}

Questionnaire items to measure the level of care burden due to home care were taken from the following: The Japanese version of the 8-item Zarit Caregiver Burden Interview (J-ZBI_8) [15], the 13-item Sense of Coherence scale (SOC_13) [16] [17], and the self-related health (SRH) questionnaire [18] [19].

The J-ZBI_8 enabled measurement of the total care burden by combining the physical, mental, and economic care burdens. The answers were scored on a scale from zero to four, in which a higher total score signified a 
more serious care burden. The SOC_13 measured the mental/physical health of the subjects (caregivers). The answers were scored on a scale from one to seven, in which a higher total score signified good mental/physical health and a large capacity to deal with stress. However, the SRH showed the subjective viewpoints of the caregivers (subjects) and indicated whether they considered themselves to be in good health or not. The answers were scored on a scale from one to five. A higher score signified that the caregiver's subjective sense of wellbeing was high.

\subsubsection{Interviews}

Interviews consisted of the following questions: "Why have you decided to give care", "How do you provide care", "How do you feel about nursing", "How do you communicate with other caregivers" and "What do you think of end-of-life care". The time needed to interview each of the 27 male caregivers was on average approximately 60 minutes.

The interviews were transcribed and analyzed based on the word-for-word records of the subjects' responses. These transcriptions were read repeatedly by the researchers. Abstracted from the contents, taking the differences among the data into consideration, the researchers then extracted subcategories. From these subcategories were found categories and ultimately core categories.

\subsection{Statistical Analysis}

After compiling the questionnaire data and interview findings, survey items were classified into groups based on their characteristics. Comparisons among the J-ZBI, SOC_13, and SRH scores were made and screened with the Mann-Whitney test for two groups and the Kruskal-Wallis test for three groups. Screening for low-order groups was performed with the Scheffe test. Correlations among the J-ZBI, SOC_13, and SRH were drawn with the Spearman's rank correlation coefficient.

Regarding the SOC_13 data, there was a missing value so its analysis used data from 26 subjects. However, the other two scales were analyzed using the data from 27 subjects. The significance level was set at $5 \%$. SPSS for Japan version 20.0 for Windows (IBM) was used for all analyses. Data analysis was conducted under supervision of the authors in order to ensure that the analyses were reliable and reasonable.

\subsection{Ethical Considerations}

This study was approved by the Ethical Review Board of the University of Shiga Prefecture. Subjects were explained the nature of the study, and its purposes. Also explained was the caveat that they could stop the interviews at any time, and that their privacy would be protected. It was also explained to the subjects in writing that the findings would be made public as an aggregate and that they will not be identified individually. Written informed consent was obtained from all subjects prior to participation in the study.

\section{Results}

\subsection{Questionnaire Results}

Table 1 shows the background information of the male caregivers (average age was $72.5 \pm 8.5$ yrs, its range was 54 - 85), the care recipients (average age was $77.2 \pm 11.6$, its range was 40 - 95), and comparisons among the J-ZBI_8, SOC_13, and SRH.

The SRH of male caregivers who were $<65$ years old was much higher as compared to those $>75$ years old ( $p$ $=0.043)$. Those with treatment of diseases showed much lower SRH as compared to those without treatment of diseases $(p=0.001)$. Male caregivers who had hobbies showed much lower J-ZBI_8 scores as compared to those without hobbies $(p=0.049)$. In other items, there were no significant differences (Table 1 ).

The SOC_13 $(p<0.01)$ and the SRH $(p<0.01)$ were significantly negatively associated with the J-ZBI_8 scores. However, there was no correlation between the SRH and SOC_13 (Table 2).

\subsection{Interview Results}

The characteristics of the male caregivers based on the interviews are shown in Table 3. Hereafter, core categories are shown in \{\}, while categories are in [], and subcategories in $<>$. The main narrative parts of each of the categories are shown in italics. 
Table 1. Background information of the male caregivers, the care recipients, and comparisons among the J-ZBI_8, SOC_13, and SRH.

\begin{tabular}{|c|c|c|c|c|c|c|c|c|c|}
\hline \multirow{2}{*}{ Characteristic } & \multirow{2}{*}{ Variable } & \multirow{2}{*}{$n$} & \multirow{2}{*}{$\%$} & \multicolumn{2}{|c|}{ J-ZBI_8 ${ }^{1)}(n=27)$} & \multicolumn{2}{|c|}{ SOC_13 $3^{2)}(n=26)$} & \multicolumn{2}{|c|}{$\mathrm{SRH}^{3)}(n=27)$} \\
\hline & & & & Mean $\pm \mathrm{SD}^{4)}$ & $p$ value $\mathrm{e}^{5)}$ & Mean \pm SD & $p$ value & Mean \pm SD & $p$ value \\
\hline \multicolumn{10}{|l|}{ Male family caregivers } \\
\hline \multirow[t]{3}{*}{ Age } & $<65$ & 5 & 18.5 & $6.6 \pm 4.4$ & \multirow{3}{*}{0.511} & $77.0 \pm 11.2$ & \multirow{3}{*}{0.450} & $4.2 \pm 0.8$ & \multirow{3}{*}{0.043} \\
\hline & $65-75$ & 11 & 40.7 & $9.6 \pm 5.9$ & & $73.2 \pm 9.5$ & & $3.0 \pm 1.1$ & \\
\hline & $>75$ & 11 & 40.7 & $10.2 \pm 6.6$ & & $69.8 \pm 12.0$ & & $2.7 \pm 1.0$ & \\
\hline \multirow[t]{2}{*}{ Employment status } & Yes & 7 & 25.9 & $7.9 \pm 5.5$ & \multirow{2}{*}{0.808} & $72.2 \pm 10.7$ & \multirow{2}{*}{0.700} & $3.4 \pm 1.3$ & \multirow{2}{*}{0.341} \\
\hline & No & 20 & 74.1 & $9.8 \pm 6.1$ & & $72.6 \pm 11.2$ & & $3.0 \pm 1.1$ & \\
\hline \multirow[t]{2}{*}{ Treatment of disease } & Yes & 19 & 70.4 & $10.2 \pm 4.1$ & \multirow{2}{*}{0.360} & $70.8 \pm 11.0$ & \multirow{2}{*}{0.216} & $2.7 \pm 1.0$ & \multirow{2}{*}{0.001} \\
\hline & No & 8 & 29.6 & $7.1 \pm 6.4$ & & $76.3 \pm 10.3$ & & $4.1 \pm 0.6$ & \\
\hline \multirow[t]{2}{*}{ Drinking } & Yes & 12 & 44.4 & $10.4 \pm 5.0$ & \multirow{2}{*}{0.152} & $70.8 \pm 12.7$ & \multirow{2}{*}{0.494} & $3.3 \pm 1.2$ & \multirow{2}{*}{0.456} \\
\hline & No & 15 & 55.6 & $8.3 \pm 6.5$ & & $74.0 \pm 9.2$ & & $2.9 \pm 1.1$ & \\
\hline \multirow[t]{2}{*}{ Smoking } & Yes & 9 & 33.3 & $9.8 \pm 5.5$ & \multirow{2}{*}{0.705} & $74.6 \pm 13.2$ & חרת ח & $3.0 \pm 0.9$ & \\
\hline & No & 18 & 66.7 & $9.0 \pm 6.2$ & & $71.6 \pm 9.9$ & 0.330 & $3.2 \pm 1.2$ & 0.031 \\
\hline Hobbies & Yes & 21 & 77.8 & $8.2 \pm 5.8$ & (1) & $73.4 \pm 11.3$ & (200 & $3.3 \pm 1.1$ & 0140 \\
\hline & No & 6 & 22.2 & $12.8 \pm 5.0$ & 0.049 & $68.8 \pm 9.0$ & 0.300 & $2.5 \pm 1.0$ & 0.140 \\
\hline Sleeping hours & $<6$ & 6 & 22.2 & $11.3 \pm 6.9$ & & $73.2 \pm 12.0$ & & $2.8 \pm 1.3$ & \\
\hline & $6-7$ & 10 & 37.0 & $7.5 \pm 4.7$ & 0.509 & $69.1 \pm 13.7$ & 0.726 & $3.4 \pm 1.0$ & 0.425 \\
\hline & $>7$ & 11 & 40.7 & $9.7 \pm 6.3$ & & $75.5 \pm 6.1$ & & $3.0 \pm 1.2$ & \\
\hline Career & $<5$ & 10 & 37.0 & $8.8 \pm 5.4$ & & $74.1 \pm 10.6$ & & $3.3 \pm 1.4$ & \\
\hline & $5-10$ & 9 & 33.3 & $8.1 \pm 5.3$ & 0.664 & $76.7 \pm 8.1$ & 0.105 & $3.3 \pm 0.9$ & 0.253 \\
\hline & $>10$ & 8 & 29.6 & $11.1 \pm 7.2$ & & $66.0 \pm 12.0$ & & $2.6 \pm 0.9$ & \\
\hline Care recipients & & & & & & & & & \\
\hline Age & $<65$ & 2 & 7.4 & $17.0 \pm 4.2$ & & $72.0 \pm 5.7$ & & $3.0 \pm 0.0$ & \\
\hline & $65-75$ & 9 & 33.3 & $8.7 \pm 7.8$ & r & $69.2 \pm 14.6$ & 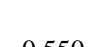 & $3.1 \pm 1.1$ & 10г \\
\hline & $75-85$ & 10 & 37.0 & $8.9 \pm 4.5$ & 0.310 & $76.2 \pm 7.8$ & 0.350 & $3.0 \pm 1.2$ & 0.195 \\
\hline & $>85$ & 6 & 22.2 & $8.2 \pm 4.1$ & & $71.2 \pm 10.3$ & & $3.3 \pm 1.4$ & \\
\hline Relationship to & Mother & 7 & 25.9 & $7.6 \pm 4.0$ & & $73.8 \pm 11.2$ & & $3.6 \pm 1.4$ & \\
\hline th & Wife & 19 & 70.4 & $9.6 \pm 6.5$ & 0.467 & $72.3 \pm 11.3$ & 0.681 & $3.0 \pm 1.0$ & 0.413 \\
\hline & Child & 1 & 3.7 & 14.0 & & 68.0 & & 3.0 & \\
\hline Diseases & Dementia & 8 & 29.6 & $8.5 \pm 5.9$ & & $70.8 \pm 1.6$ & & $3.1 \pm 1.1$ & \\
\hline & $\begin{array}{l}\text { Cerebrovascular } \\
\text { disease }\end{array}$ & 9 & 33.3 & $11.7 \pm 7.6$ & 0.597 & $72.4 \pm 11.7$ & 0.722 & $3.3 \pm 0.9$ & 0.842 \\
\hline & $\begin{array}{c}\text { Neurological } \\
\text { disease and others }\end{array}$ & 10 & 37.0 & $7.5 \pm 2.4$ & & $75.0 \pm 9.8$ & & $2.9 \pm 1.5$ & \\
\hline Degree of autonomy ${ }^{7)}$ & Mild & 8 & 29.6 & $11.6 \pm 8.8$ & & $73.9 \pm 9.6$ & & $2.9 \pm 0.8$ & \\
\hline & Moderate & 10 & 37.0 & $9.1 \pm 4.1$ & 0.923 & $69.1 \pm 9.3$ & 0.320 & $3.1 \pm 1.4$ & 0.598 \\
\hline & Severe & 9 & 33.3 & $7.3 \pm 4.0$ & & $75.4 \pm 13.8$ & & $3.3 \pm 1.0$ & \\
\hline
\end{tabular}

${ }^{1)}$ The Japanese version of the zarit caregiver burden interview; ${ }^{2)}$ Sense of coherence; ${ }^{3)}$ Self-related health; ${ }^{4)}$ Standard deviation; ${ }^{5)}$ Test between the two groups were used the Mann-Whitney test, and test of the three groups were used the Kruskal-Wallist test; ${ }^{6}$ Neurological disease and others: Parkinson's disease, Spinal cerebellar degeneration, Muscular dystrophy, Basal ganglia disease, Leukoencephalopathy, Multiple rheumatoid arthritis, and Idiopathic thrombocytopenia thrombocytopenia; ${ }^{7}$ Degree of autonomy: Mild: It can move alone generally in the house but can not go out unassisted, Moderate: In the house, living on the bed of what keep the sitting position is the main, some assistance is needed; Severe: It was necessary to take care of daily life excretion assistance, help with eating, such as change of clothes, and spend all day in bed. 
Table 2. The correlation between the J-ZBI_8, the SOC_13, and the SRH.

\begin{tabular}{cccc}
\hline Variable & J-ZBI_8 ${ }^{1)}(n=27)$ & SOC_13 $3^{2)}(n=26)$ & SRH $^{3)}(n=27)$ \\
\hline J-ZBI_8 & 1.000 & & \\
SOC_13 & $-0.411^{*}$ & 1.000 & \\
SRH & $-0.391^{*}$ & 0.304 & 1.000 \\
\hline
\end{tabular}

${ }^{*} p<0.01$. Spearman's rank correlation coefficient; ${ }^{1)}$ The Japanese version of the Zarit Caregiver Burden Interview; ${ }^{2}$ Sense of Coherence; ${ }^{3)}$ Self-related health.

Table 3. Characteristics of male family caregivers of this study.

\begin{tabular}{|c|c|c|}
\hline Core category & Category & Subcategory \\
\hline \multirow{7}{*}{$\begin{array}{l}\text { They considered home care } \\
\text { to be their primary occupation }\end{array}$} & They were particular about methods of care. & $\begin{array}{l}\text { - They do not want to leave home care to } \\
\text { somebody else. } \\
\text { - They want to take care of their family in } \\
\text { their own way. } \\
\text { - They want their family to do what they ask } \\
\text { the care recipient. }\end{array}$ \\
\hline & $\begin{array}{l}\text { They learned how to provide home care by } \\
\text { themselves. }\end{array}$ & $\begin{array}{l}\text { - They can use their past experiences in home care. } \\
\text { - They learn how to care from books. }\end{array}$ \\
\hline & & - $\quad$ They seldom attend meetings for caregivers. \\
\hline & $\begin{array}{l}\text { They used their social intelligence in } \\
\text { home care. }\end{array}$ & • They are good at time management. \\
\hline & & $\begin{array}{l}\text { - They don't like it when others can see their distress. } \\
\text { - They choose nursing-care services systems by } \\
\text { themselves to make their life easier. }\end{array}$ \\
\hline & $\begin{array}{l}\text { They always provided home care while } \\
\text { keeping the future in mind. }\end{array}$ & $\begin{array}{l}\text { - They do their best so that the condition of } \\
\text { their family will improve. }\end{array}$ \\
\hline & & $\begin{array}{l}\text { - They have prepared for what to do when } \\
\text { their family faces an emergency or a family } \\
\text { member is in the terminal phase. }\end{array}$ \\
\hline
\end{tabular}

One main characteristic of male family home caregivers was found as a core category they considered home care to be their primary occupation , which consisted of the four categories listed below.

The category [they were particular about methods of care] consisted of the following three subcategories: $<$ they do not want to leave home care to somebody else >, <they want to take care of their family in their own way $>$, and $<$ they want their family to do what they ask the care recipient $>$. This category was demonstrated by responses such as:

I think I am doing as much as I can. In no other place and in no other home do they offer better service than I do. Even though my wife suffers from dementia, I cannot stop wanting her to do what I want her to. As a result, I get angry at her when she does not obey me. I later feel sorry that I could not control my emotions. It often happens that we get angry with those who suffer from the disease.

The category [they learned how to provide home care by themselves] consisted of the following three subcategories: <they can use their past experiences in home care $>$, <they learn how to nurse from books $>$, and <they seldom attend meetings for caregivers $>$. This category was demonstrated by responses such as:

I study how to nurse almost $100 \%$ by myself. I read books on home care. I often go to libraries. When doctors told me to give rehabilitation training to my wife.

I read all kinds of books on strokes and/or rehabilitation. I have heard about meetings for caregivers, but I do not like to attend them and share my hardships and the like. I do not think I can get any good information about home care there. 
The category [they used their social intelligence in home care] consisted of the following three subcategories: $<$ they are good at time management $>$, $<$ they don't like it when others can see their distress $>$, and $<$ they choose nursing-care services systems by themselves to make their life easier $>$. This category was demonstrated by responses such as:

What I am proud of is that I live a well-regulated life due to taking care of my wife. I am proud that I make a daily schedule for my life.

Since my wife began going to daycare centers, I have leisure time from 9 AM to 4 PM. During that time I can do things I could not do before. I can relieve stress by going and buying some hobby books from bookstores.

I love sports. I play table tennis in the athletic gym on Tuesdays and Fridays. I also enjoy gardening.

There are a variety of support systems that elderly persons can enjoy. The problem is that we cannot use them without applying. I have learned how to use these systems. If I did not, I could not enjoy them now.

The category [they always provided home care while keeping the future in mind] consisted of the following two subcategories: <they do their best so that the condition of their family will improve> and <they have prepared for what to do when their family faces an emergency or a family member is in the terminal phase $>$. This category was demonstrated by responses such as:

As I heard that coloring was good for my wife to train her fingertips, I help her do it, and I let her walk inside the house without her wheelchair. In this way, I was able to help her learn to walk again at home. Because of this, she has become able to talk well enough and to walk by herself with a walking stick. I think my wife and I can be proud of this. In my wife's case, there is no doubt that I will be in charge of her care as long as I stay healthy. If she gets acute pneumonia or other diseases, I will have to hospitalize her as I cannot perform the required emergency procedures. It is not certain whether doctors will be able to save her or not, though. I am determined to do my best and not let her die in a hospital or home as long as I am healthy.

\section{Discussion}

Based on the results of the questionnaires used in this study, examining male caregivers' sense of care burden, capacity to deal with stress, and subjective sense of well-being, it was shown that the care burden was comparatively low among those who were good at relieving stress or had a balanced sense of well-being.

The average SOC_13 scores in this study were higher compared to those reported by Tanaka et al. for males in the general population $(64.6 \pm 12, n=167)$ [20]. Therefore, those surveyed in this study were good at relieving stress.

Regarding the correlation between the capacity to deal with stress and the sense of care burden, it was shown that the latter scores became smaller as the former scores increased. This result was the same as that reported by Matsushita et al. [21]. In other words, because those surveyed in this study were able to cope with the condition of the care recipient's disease and the changes in day-to-day living, they did not feel a great deal of bitterness to take care of a family member.

The types and seriousness of the care recipients' diseases did not directly affect the male caregivers' sense of care burden, capacity to deal with stress, or their subjective sense of care burden. Furthermore, considering that those with hobbies tended to feel less bitter towards home care, and relish the importance of leisure time for caregivers.

Based on the characteristics of the male caregivers found through the interviews, these observations were made: The category [they were particular about methods of care] showed that they took pride in the level of care they provided and could not leave the care recipient in the hands of other people because of their conscientiousness. It seemed as if they considered nursing to be their primary occupation and were determined to make a sincere effort to do a good job. Since they considered home care to be their new job, they stuck to their own methods and performed home care just as they wanted. They also seemed to think that their family should obey them and do what they wanted. Home care enabled them to nurture their feelings of love for their family and also created bonds of affection within their families.

On the other hand, it is possible that wanting things their own way could lead them closing themselves off from their families and preventing them from communicating with other people. For example, it was common 
for the caregiver to be offended when they could not have their own way in unexpected situations. While the male caregivers were likely to provide good home care, it is conceivable that their perfectionism might lead to them mistreating family members. With this in mind, the researchers have concluded that it is even more important to support these caregivers in their quest to care for their loved ones.

The category [they learned how to provide home care by themselves] showed that the male caregivers were undertaking the challenge of learning nursing methods in their own way in the new phase of the latter half of their lives. They managed to acquire the necessary information about home care from books and did not depend on other people. Even though they were aware of social nursing care services such as caregivers' meetings, they would not participate in them because they did not think that meeting others and sharing personal stories would help them solve their home nursing care problems.

A previous study in Japan [22] showed that less than half of male caregivers were in need of emotional support in nursing care. Most of them did not search for emotional support through peer counseling. Therefore, the present study clarified that a plan for male caregivers to obtain the knowledge and skills needed for nursing care is necessary.

The category [they used their social intelligence in hone care] showed that male caregiver behaviors were based on the skills they obtained from their experience in the workforce. This was clearly demonstrated by their time management skills. For example, the caregivers who had been enjoying their hobbies before they started home care were sure to continue them by trying to make time for their leisure activities. Those with hobbies were also found to have a lower sense of care burden compared to those who had no hobbies. In other words, these caregivers were using their leisure time to relieve the stress of home care. The present study showed that male caregivers knew how to work off stress and keep themselves stable by making use of their life experiences. Furthermore, the male caregivers showed excellent competency in researching and selecting social care services and using them to their fullest extent as if they were taking full advantage of the skills they had obtained in their former careers. In this way, they were able to master the social support systems offered. Therefore, even when they were in distress, they were inclined to solve their problems while trying to avoid others seeing their troubles as much as possible.

The category [they always provided home care while keeping the future in mind] showed that male caregivers were always concerned about their family's future while providing home care. For example, while they were struggling with home care, they pictured the care recipient getting better and better. They hoped the care recipient would get well again after rehabilitation and they convincingly set an objective for it. This behavior could be representative of the same commitment to success they had given their former careers.

In addition, male caregivers prepared well as to what to do when the care recipient is facing an emergency particularly end-of-life care. These preparations seemed flexible, indicating that the caregivers may not stick to providing final care at home. This attitude came from their past social experiences and their decisiveness and ability to take action. Based on their own capabilities to provide home care as well as their emotions, they could deal with the deterioration of their loved ones with their care recipient's health or death because they had prepared for it.

The results of the analyses of the questionnaires and interview data showed that male caregivers seemed to alleviate their sense of care burden by working off stress while utilizing nursing care services that enabled them to change their moods.

There was a limitation in this study. Because all subjects were introduced by home nursing stations or elderly care support center, they were able to provide nursing care to some extent. Additionally, the number of subjects was low and they may not be representative of male caregivers in the general population. Therefore, a future study with a larger number and variety of subjects should be conducted in order to obtain more generalizable results.

\section{Conclusion}

The sense of care burden for the 27 male family home caregivers in this study was not significant particularly when they were able to resist stress or they had a good subjective sense of health. The type or seriousness of the care recipients' diseases was not related to the male caregivers' sense of home care burdens, capacity to deal with stress, or subjective sense of health. Furthermore, based on the results of the interviews of male caregivers, it was revealed that they could alleviate the burdens of home care if they used their leisure time to change their 
moods and knew how to use nursing-care services. It could be said that they were caregivers who could work through the care recipients' diseases or day-to-day changes as if providing nursing care was their occupation. By utilizing their social skills, they were successful in getting over their hardships.

\section{Acknowledgements}

We would like to sincerely thank the subjects of the study and the staff of the home-visit service station who introduced them to us. All of the coauthors declare that they have no direct conflict of interest or grant support that is directly related to the content of the study.

\section{References}

[1] UNFPA and Help Age International (2012) Ageing in the Twenty-First Century: A Celebration and a Challenge. http://unfpa.org/ageingreport/ https://www.unfpa.org/public/home/publications/pid/11584

[2] Carter, R. (2008) Addressing the Caregiving Crisis. Preventing Chronic Disease, 5. http://www.cdc.gov/pcd/issues/2008/jan/07_0162.htm

[3] Zarit, S.H., Reever, K.E. and Bach-Peterson, J. (1980) Relatives of the Impaired Elderly: Correlates of Feelings of Burden. The Gerontologist, 20, 649-655.

http://www.rgpc.ca/best/GiiC\%20Resources/GiiC/pdfs/3\%20Caregiver\%20Support\%20-\%20The\%20Zarit\%20Burden \%20Interview.pdf http://dx.doi.org/10.1093/geront/20.6.649

[4] Lawton, M.P., Kleban, M.H., Moss, M., Rovine, M. and Glicksman, A. (1989) Measuring Caregiving Appraisal. Journal of Gerontology, 44, 61-71. http://dx.doi.org/10.1093/geronj/44.3.P61

[5] Ekwall, A.K. and Hallberg, I.R. (2007) The Association between Caregiving Satisfaction, Difficulties and Coping among Older Family Caregivers. Journal of Clinical Nursing, 16, 832-844. http://dx.doi.org/10.1111/j.1365-2702.2006.01382.x

[6] Wilson-Genderson, M., Pruchno, R.A. and Cartwright, F.P. (2009) Effects of Caregiver Burden and Satisfaction on Affect of Older End Stage Renal Disease Patients and Their Spouses. Psychology and Aging, 24, 955-967. http://dx.doi.org/10.1037/a0017368

[7] Pinquart, M. and Sorensen, S. (2007) Correlates of Physical Health of Informal Caregivers: A Meta-Analysis. The Journals of Gerontology Series B: Psychological Sciences and Social Sciences, 62, 126-137. http://dx.doi.org/10.1093/geronb/62.2.P126

[8] Lutz, B.J., Young, M.E., Cox, K.J., Martz, C. and Creasy, K.R. (2011) The Crisis of Stroke: Experiences of Patients and Their Family Caregivers. Topics in Stroke Rehabilitation, 18, 786-797. http://dx.doi.org/10.1310/tsr1806-786

[9] Davis, L.L., Gilliss, C.L., Deshefy-Longhi, T., Chestnutt, D.H. and Molloy, M. (2011) The Nature and Scope of Stressful Spousal Caregiving Relationships. Journal of Family Nursing, 17, 224-240. http://dx.doi.org/10.1177/1074840711405666

[10] Provisional Translation by Cabinet Office (2014) Choice for the Future < Reference Charts> Committee for Japan's Future.

http://www5.cao.go.jp/keizai-shimon/kaigi/special/future/chuukanseiri/04_e.pdf\#search='In+2012+in+Japan\%2C+over $+24 \% 25+$ of +the+general+population+was+\%3E65+years+old+and+Japan+presently+has+the+highest+longevity+rate +in+the+world

[11] Kneipp, S.M., Castleman, J.B. and Gailor, N. (2004) Informal Caregiving Burden: An Overlooked Aspect of the Lives and Health of Women Transitioning from Welfare to Employment? Public Health Nursing, 21, 24-31. http://dx.doi.org/10.1111/j.1525-1446.2004.21104.x

[12] Mc Donnell, E. and Ryan, A. (2013) Male Caregiving in Dementia: A Review and Commentary. Dementia, 12, 238250. http://dx.doi.org/10.1177/1471301211421235

[13] Robinson, C.A., Bottorff, J.L., Pesut, B., Oliffe, J.L. and Tomlinson, J. (2014) The Male Face of Caregiving: A Scoping Review of Men Caring for a Person with Dementia. American Journal of Men's Health, 8, 409-426. http://dx.doi.org/10.1177/1557988313519671

[14] http://www8.cao.go.jp/kourei/whitepaper/w-2012/zenbun/s1_2_3_02.html

[15] Kumamoto, K. and Arai, Y. (2004) Validation of "Personal Strain” and "Role Strain”: Subscales of the Short Version of the Japanese Version of the Zarit Burden Interview (J-ZBI_8). Psychiatry and Clinical Neurosciences, 58, 606-610. http://dx.doi.org/10.1111/j.1440-1819.2004.01310.x 
[16] Eriksson, M. and Lindström, B. (2005) Validity of Antonovsky’s Sense of Coherence Scale: A Systematic Review. Research Report. Journal of Epidemiology and Community Health, 59, 460-466. http://dx.doi.org/10.1136/jech.2003.018085

[17] Togari, T. and Yamazaki, Y. (2005) Examination of the Reliability and Factor Validity of 13-Item Five-Point Version Sense of Coherence Scale. Japanese Journal of Health and Human Ecology, 71, 168-182. http://dx.doi.org/10.3861/jshhe.71.168

[18] Abdollahpur, I., Nedjat, S., Noroozian, M., Salimi, Y. and Majdzadeh, R. (2014) Caregiver Burden: The Strongest Predictor of Self-Rated Health in Caregivers of Patients with Dementia. Journal of Geriatric Psychiatry and Neurology, 27, 172-180. http://dx.doi.org/10.1177/0891988714524627

[19] Singh-Manoux, A., Martikainen, P., Ferrie, J., Zins, M., Marmot, M. and Goldberg, M. (2006) What Does Self-Rated Health Measure? Results from the British Whitehall II and French Gazel Cohort Studies. Journal of Epidemiology and Community Health, 60, 364-372. http://dx.doi.org/10.1136/jech.2005.039883

[20] Tanaka, S., Masumoto, T., et al. (2001) Strengthening of Local Residents’ Sense of Coherence (SOC), a Longitudinal Study. Japanese Journal of Nursing Research, 33, 75-82.

[21] Matsushita, M., Ishikawa, T., Koyama, A., Hasegawa, N., Ichimi, N., Yano, H., et al. (2014) Is Sense of Coherence Helpful in Coping with Caregiver Burden for Dementia? Psychogeriatrics, 14, 87-92. http://dx.doi.org/10.1111/psyg.12050

[22] Isse, T. (2001) Elderly Caregivers of Demented Spouses-The Situation of Elderly Male Caregivers. Nara Women's University. Research Journal of Living Science, 48, 28-37. 
Scientific Research Publishing (SCIRP) is one of the largest Open Access journal publishers. It is currently publishing more than 200 open access, online, peer-reviewed journals covering a wide range of academic disciplines. SCIRP serves the worldwide academic communities and contributes to the progress and application of science with its publication.

Other selected journals from SCIRP are listed as below. Submit your manuscript to us via either submit@scirp.org or Online Submission Portal.
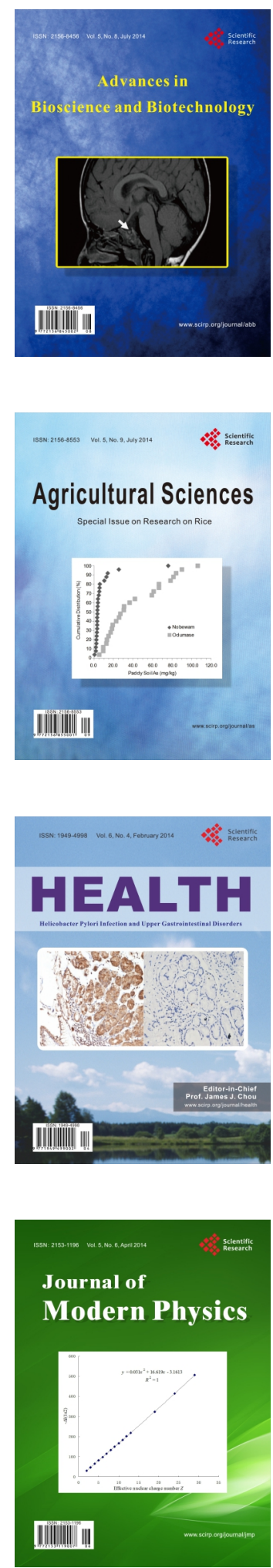
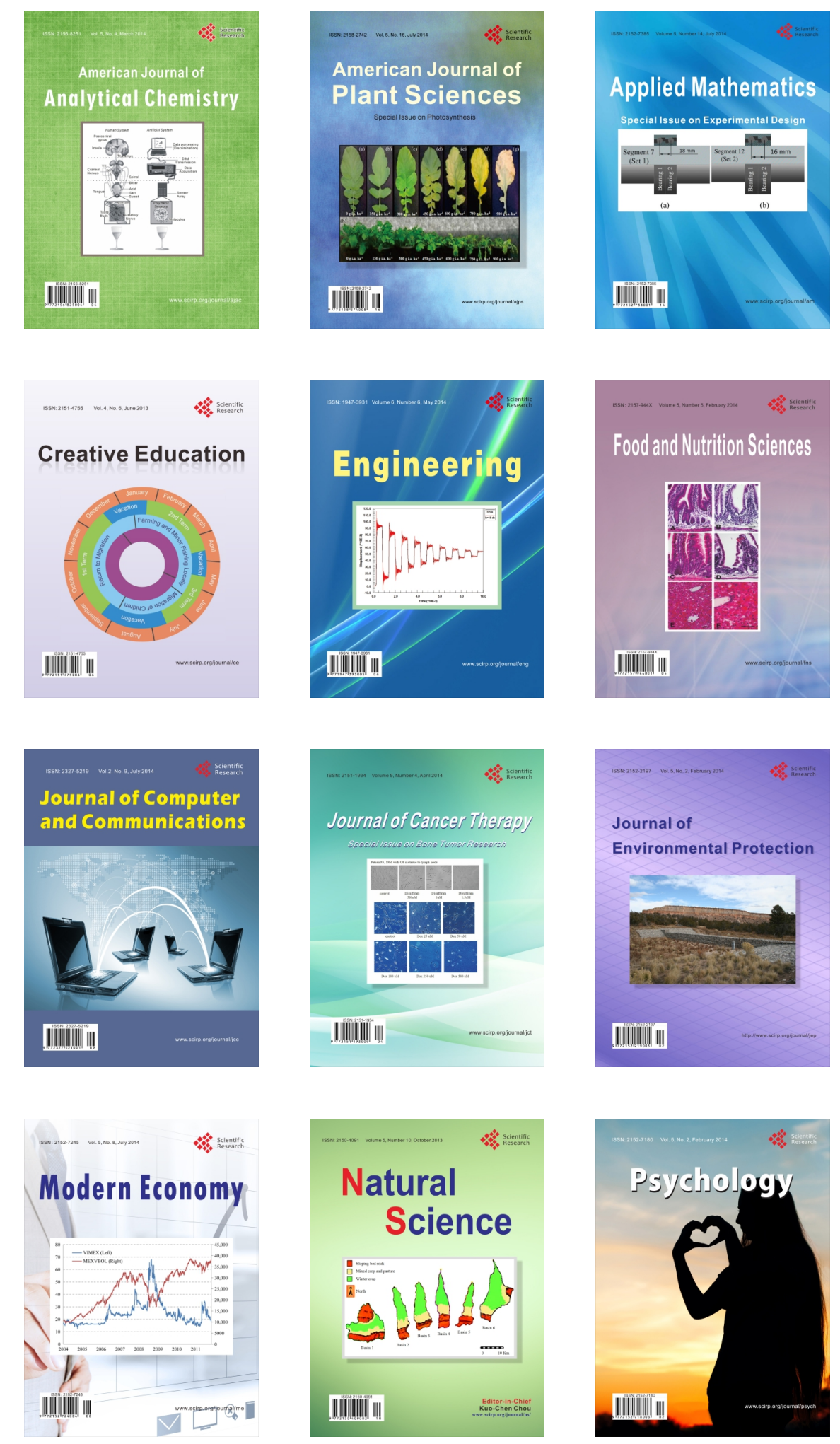